\title{
Analysis of shrinkage deformations in concrete structures
}

\author{
M P DIVAKAR ${ }^{1}$ and W H DILGER ${ }^{2}$ \\ ${ }^{1}$ Department of Civil Engineering, Arizona State University, Tempe, AZ \\ 85287, USA \\ ${ }^{2}$ Department of Civil Engineering, The University of Calgary, Calgary, \\ Alberta T2N 1N4, Canada
}

\begin{abstract}
An analytical method for predicting shrinkage deformations in both cracked and uncracked states is discussed. The validity of this method was verified by conducting an experimental investigation in which deformations due to shrinkage were measured for more than 300 days in the laboratory. The curvatures due to shrinkage were found to be different in cracked and uncracked states. The introduction of compression reinforcement was found to reduce the shrinkage curvatures, whereas increase in tension reinforcement was found to increase shrinkage curvatures. Equations presented here for computing these deformations compare fairly well with experimental data and are recommended to be used in the serviceability analysis of concrete members.
\end{abstract}

Keywords. Shrinkage deformations; concrete structures; compression reinforcement; tension reinforcement; crack width.

\section{Introduction}

An important criterion in the limit state design of concrete structures is serviceability. Concrete structures, once designed and built, are expected to perform well against fluctuations in loads, temperature and environmental changes with duration of time. Typically, this performance is judged by checking deformations (deflections) and crack widths with respect to some allowable limits, usually stipulated by building codes such as IS-456 or ACI-318. Satisfying serviceability requirements in addition to strength requirements has therefore become an essential part of modern structural concrete design.

Deformations in concrete structures, whether loaded or not, increase with time. This is mainly due to creep and shrinkage of concrete. While creep acts in conjunction with shrinkage in loaded concrete members, many unloaded structures exhibit significant deformations due to shrinkage alone. Reinforcing steel inhibits shrinkage, inducing compressive stresses in steel, equilibrated by tensile stresses in concrete. When the reinforcement is unsymmetric, the resuiting non-uniform stress distribution and accompanying warping cause curvature in the same direction as those

A list of symbols is given at the end of the paper. 
caused by the loads for which the structure was designed and reinforced. Symmetrical reinforcement with non-uniform shrinkage also leads to shrinkage warping. The extent up to which shrinkage contributes to the overall deformations is debatable. The ACl Committee 435 (1966, Reaffirmed 1979) is of the opinion that this contribution could be as high as $30 \%$ of the total deflections (except for shallow members with small live loads).

An accurate assessment of the effect of shrinkage in concrete structures is rather complicated owing to the complex nature of the shrinkage mechanism itself as well as other factors such as internal micro-cracking and stress redistribution caused by shrinkage and creep. These apparent mechanisms are not fully understood and are difficult to model. However, several methods based on some simplifying assumptions are available in the literature to predict deformations due to shrinkage (Trost \& Mainz 1969; Dilger \& Neville 1970; Elvery \& Shafi 1970; CEB-FIP 1981; Dilger 1982) and some of them are purely empirical (Beeby 1973; Branson 1977). Most of these deal with concrete structures drying symmetrically and few (Abdul Wahab \& Jaffar 1983) deal with unsymmetric drying conditions.

This paper is mainly concerned with the deformation behaviour of unloaded precracked reinforced concrete members subjected to drying shrinkage. For this purpose, an experimental programme was conducted (Divakar 1983). The concept of "creep transformed section" (Dilger \& Neville 1970; Dilger 1982) has been used to formulate shrinkage deformations for uncracked members and has been extended to cracked members (Divakar 1983; Divakar \& Dilger 1985). The analytical method is compared with experimental results. Note that the analytical method discussed here is quite general, applicable to members with non-uniform shrinkage and composite construction. It can be easily modified to prestressed concrete.

\section{Theoretical considerations}

Most structural concrete members built on the basis of ultimate strength design are cracked under service loads. It is essential to estimate deformations accurately in this state. Similar to basic flexural deformations, the shrinkage deformations of a cracked member are higher than those of uncracked members.

It is logical to assume that the total deformation of a cracked member is the combined property of both cracked and uncracked sections. A rational procedure for estimating the total deformation is to distribute the deformations in cracked and uncracked sections by means of a distribution ratio which describes the extent up to which cracking has taken place. This procedure has been recommended by CEB-FIP (1981) in the so-called "bilinear" method. According to this method, the mean curvature due to shrinkage of a cracked member is given by,

$$
\psi_{s h m}=(1-\zeta) \psi_{s h 1}+\xi \psi_{s k 2} \text {, }
$$

where $\psi_{s h 1}$ and $\psi_{s h 2}$ are the shrinkage curvatures in the uncracked and cracked states respectively, and $\zeta$ is the distribution ratio given by the following equation.

$$
\zeta=1-\beta_{1} \beta_{2}\left(\sigma_{s r} / \sigma_{s}\right)^{2},
$$

where $\beta_{1}=1.0$ for deformed bars, and $\beta_{2}=1.0$ at first loading and 0.5 for loads applied in sustained manner. It can be seen from the above expression that the distribution ratio has been formulated for basic flexural deformations. In both 

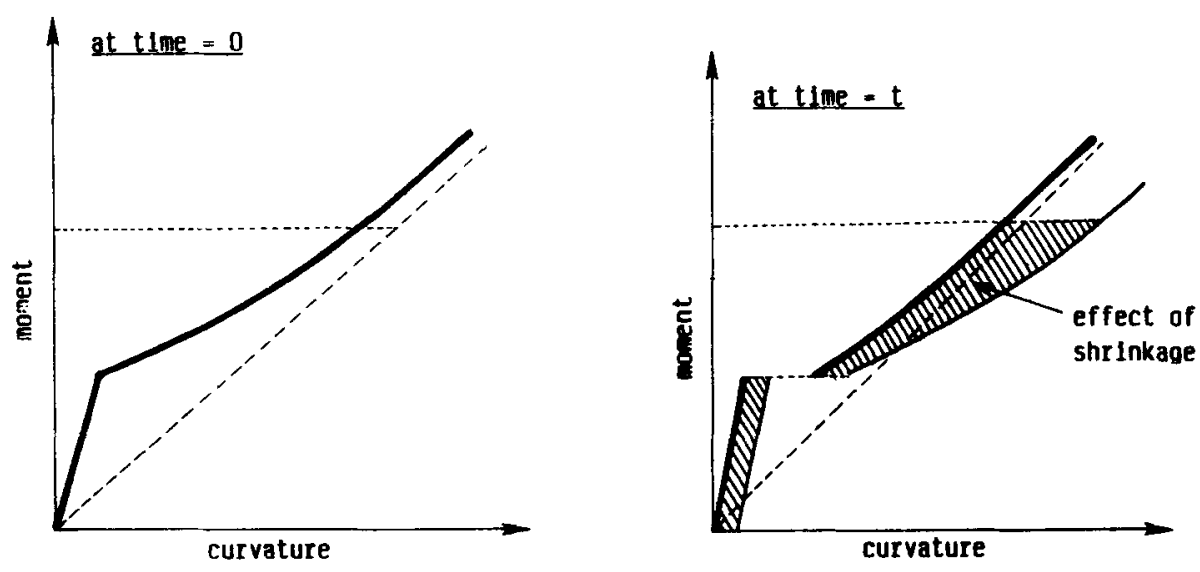

Figure 1. Effect of shrinkage on flexural deformations (CEB-FIP 1981).

cracked and uncracked states, shrinkage is independent of the load level and creates a parallel shift of the moment curvature diagram (see figure 1). It is proposed here to use the same distribution ratio for shrinkage curvatures. It is interesting to note that the form of (1) is similar to that proposed by Branson (1977) for calculating the effective moment of inertia, which can be written as,

$$
E I_{\text {eff }}=\mu E I_{\text {uncracked }}+(1-\mu) E I_{\text {cracked }},
$$

where $\mu=\left(M_{c r} / M_{a}\right)^{3}$ can be treated as a parameter describing the extent of cracking.

\subsection{Shrinkage curvature at an uncracked section}

In the analysis of uncracked sections, it is normally assumed that concrete is homogeneous and elastic with adequate bond between steel and concrete, and that shrinkage develops at the same rate as creep. It is also assumed that shrinkage develops uniformly across the cross-section. Note that the stresses developed by shrinkage are relieved to some extent by creep of concrete.

Figure 2 shows the forces and strains due to shrinkage in a section with two layers
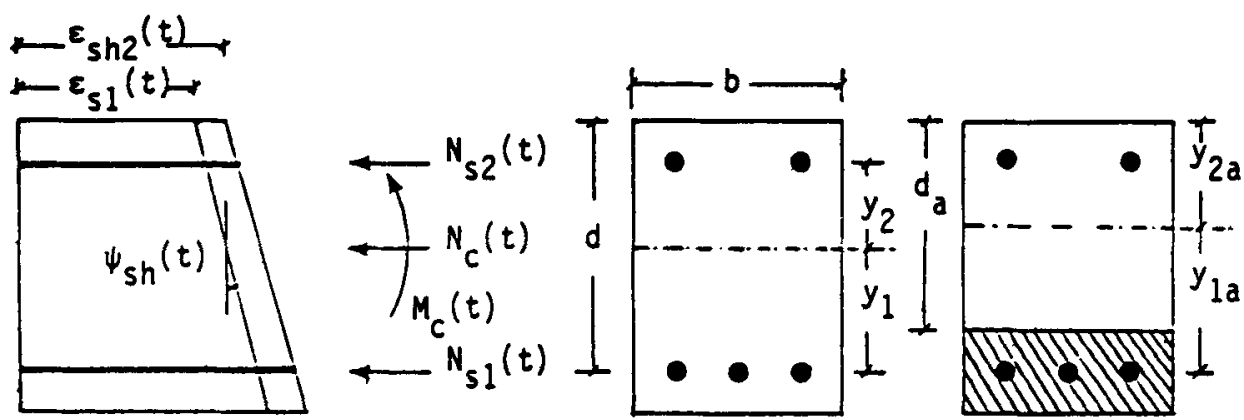

$\longleftarrow \varepsilon_{s 1}(t)$

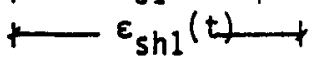

Figure 2. Forces and strains due to shrinkage. 
of steel and non-uniform shrinkage gradient. If no forces are present at the beginning of shrinkage, the sum of increments in these forces are zero, i.e.,

$$
\begin{aligned}
& \Delta N_{c}(t)=-\Delta N_{s 1}(t)-\Delta N_{s 2}(t), \\
& \Delta M_{c}(t)=-\Delta N_{s 1}(t) y_{1}-\Delta N_{s 2}(t) y_{2},
\end{aligned}
$$

i.e.,

$$
\begin{aligned}
& \Delta N_{c}(t)=-E_{s}\left[\Delta \varepsilon_{s 1}(t) A_{s 1}+\Delta \varepsilon_{s 2}(t) A_{s 2}\right], \\
& \Delta M_{c}(t)=-E_{s}\left[\Delta \varepsilon_{s 1}(t) A_{s 1} y_{1}+\Delta \varepsilon_{s 2}(t) A_{s 2} y_{2}\right],
\end{aligned}
$$

where $\Delta \varepsilon_{s}(t)$ represents the change in strain of steel reinforcement due to shrinkage. Note that $y$ is positive below the centroidal axis.

The stress change in concrete due to shrinkage is given by

$$
\Delta \sigma_{c}(t)=\left[\Delta N_{c}(t) / A_{c}\right]+\left[\Delta M_{c}(t) / I_{c}\right] y,
$$

where $A_{c}$ and $I_{c}$ refer to the net concrete section.

The time dependent strain in concrete at any instant can be obtained by the following equation (Trost \& Mainz 1969):

$$
\begin{aligned}
\varepsilon_{c}(t)= & {\left[\sigma_{c 0} / E\left(t_{0}\right)\right]\left[1+\varphi\left(t, t_{0}\right)\right]+\left\{\left[\sigma_{c}(t)-\sigma_{c 0}\right] / E\left(t_{0}\right)\right\}\left[1+\chi \varphi\left(t, t_{0}\right)\right] } \\
& +\varepsilon_{s h}\left(t, t_{0}\right) .
\end{aligned}
$$

For shrinkage effects alone, $\sigma_{c 0}=0$. Substituting for $\Delta \sigma(t)$ from (8) and simplifying, we get,

$$
\begin{aligned}
\Delta \varepsilon_{1}(t)= & \varepsilon_{s h 1}\left(t, t_{0}\right)-\Delta \varepsilon_{s 1}(t) \rho_{1} n_{0}\left(1+y_{1}^{2} / r^{2}\right)\left[1+\chi \varphi\left(t, t_{0}\right)\right] \\
& -\Delta \varepsilon_{s 2}(t) \rho_{2} n_{0}\left(1+y_{1} y_{2} / r^{2}\right)\left[1+\chi \varphi\left(t, t_{0}\right)\right] .
\end{aligned}
$$

Similarly, $\Delta \varepsilon_{2}(t)$ can be formulated.

We now introduce the following coefficients:

$$
\begin{aligned}
& n^{*}=n_{0}\left[1+\chi \varphi\left(t, t_{0}\right)\right], \\
& \beta_{11}=\rho_{1} n^{*}\left[1+\left(y_{1}^{2} / r^{2}\right)\right], \\
& \beta_{12}=\rho_{1} n^{*}\left[1+\left(y_{1} y_{2} / r^{2}\right)\right], \\
& \beta_{21}=\rho_{2} n^{*}\left[1+\left(y_{1} y_{2} / r^{2}\right)\right], \\
& \beta_{22}=\rho_{2} n^{*}\left[1+\left(y_{2}^{2} / r^{2}\right)\right], \\
& \beta_{\mathrm{D}}=1 /\left[\left(1+\beta_{11}\right)\left(1+\beta_{22}\right)-\beta_{12} \beta_{21}\right],
\end{aligned}
$$

where, $\rho_{1}=A_{s} / A_{c}, \rho_{2}=A_{s}^{\prime} / A_{c}$ and $r^{2}=I_{c} / A_{c}$. Note that in this analysis, the initial modular ratio $n_{0}$ is replaced by a time dependent modular ratio $n^{*}$ defined above.

With these coefficients (10) becomes,

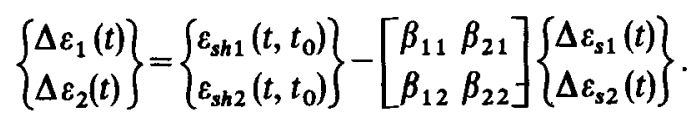

Compatibility of strains requires that $\Delta \varepsilon_{1}(t)=\Delta \varepsilon_{s 1}(t)$. Further, if we assume that the shrinkage strains are uniform throughout the cross-section, the above equation 
simplifies to,

$$
\left\{\begin{array}{l}
\Delta \varepsilon_{s 1}(t) \\
\Delta \varepsilon_{s 2}(t)
\end{array}\right\}=\beta_{\mathrm{D}} \varepsilon_{s h}\left(t, t_{0}\right)\left\{\begin{array}{l}
1+\beta_{22}-\beta_{21} \\
1+\beta_{11}-\beta_{12}
\end{array}\right\} .
$$

The stresses in steel can be calculated by multiplying the strains by the modulus of elasticity of steel. Further, the stresses in concrete are,

$$
\left\{\begin{array}{l}
\Delta \sigma_{1}(t) \\
\Delta \sigma_{2}(t)
\end{array}\right\}=-\frac{E_{s}}{n^{*}}\left[\begin{array}{ll}
\beta_{11} & \beta_{21} \\
\beta_{12} & \beta_{22}
\end{array}\right]\left\{\begin{array}{l}
\Delta \varepsilon_{s 1}(t) \\
\Delta \varepsilon_{s 2}(t)
\end{array}\right\} .
$$

The negative sign indicates that the stresses in concrete are tensile.

The curvatures due to shrinkage can be obtained from (12), which after simplification becomes,

$$
\psi_{s h 1}\left(t, t_{0}\right)=\left[\beta_{\mathrm{D}} \varepsilon_{s h}\left(t, t_{0}\right) /\left(y_{1}-y_{2}\right)\right]\left(\beta_{22}+\beta_{12}-\beta_{11}-\beta_{21}\right) .
$$

\subsection{Shrinkage curvature at a cracked section}

At a cracked section, the shrinkage curvature is largely due to the shrinkage of the uncracked concrete. Additional shrinkage due to cracks in the tension zone has an opposite effect on shrinkage curvature and has been neglected here for simplicity. The shrinkage curvature at a cracked section is formulated in a similar way, but instead of assuming the beam to be cracked up to the neutral axis (which results in an overestimation of curvatures), it is assumed to be cracked up to a depth $d_{a}=0.7 \mathrm{~h}$ known as the 'active depth' of the section (see figure 2). This quantity is based on the analysis made by Shafi (1967) which indicated that the part of concrete below the neutral axis, where the maximum tensile stress exceeds 2-3 times the modulus of rupture, may be disregarded for practical shrinkage deflection calculations.

Hence, the coefficients are now computed for the active section (subscript $a$ ) and the shrinkage curvature at a cracked section can be written as,

$$
\psi_{s h 2}\left(t, t_{0}\right)=\left[\beta_{\mathrm{Da}} \varepsilon_{s h}\left(t, t_{0}\right)\left(\beta_{22 a}+\beta_{12 a}-\beta_{11 a}-\beta_{21 a}\right)\right] /\left(y_{1 a}-y_{2 a}\right) \text {. }
$$

The expressions of (14) and (13) are used in (1) to determine the mean shrinkage curvature of a cracked member.

It should be mentioned here that the constant $\beta_{2}$ in (2) has two values; 1.0 at first loading and 0.5 for loads applied in a sustained manner, which accounts for 'decay' of tension stiffening and other effects. Since this is not the situation in case of shrinkage deformations, it is recommended that $\beta_{2}=1.0$ be used.

The maximum deflection for a member of $\operatorname{span} L$ from curvatures can be predicted using the following equation:

$$
\Delta_{s h}\left(t, t_{0}\right)=\alpha \psi_{s h m}\left(t, t_{0}\right) L^{2}
$$

where

$$
\begin{aligned}
\alpha & =0.500 & & \text { cantilevers } \\
& =0.125 & & \text { simply supported beams } \\
& =0.086 & & \text { propped cantilevers } \\
& =0.063 & & \text { fixed beams. }
\end{aligned}
$$

These values can be easily verified by the moment area method. 
Table 1. Details of test beams.

\begin{tabular}{|c|c|c|c|c|c|}
\hline $\begin{array}{l}\text { Beam } \\
\text { designation }\end{array}$ & $\begin{array}{l}\text { Reinforcement } \\
\left(\mathrm{mm}^{2}\right)\end{array}$ & $\begin{array}{c}\text { Compressive } \\
\text { strength }(\mathrm{MPa})\end{array}$ & $\begin{array}{c}\text { Split tensile } \\
\text { strength (MPa) }\end{array}$ & $\begin{array}{l}\text { Age at testing } \\
\text { (days) }\end{array}$ & $\begin{array}{l}\text { Total test } \\
\text { load }(\mathbf{k N})\end{array}$ \\
\hline $\begin{array}{l}\text { A1 } \\
\text { A2 }\end{array}$ & $\begin{array}{l}A_{\mathrm{s}}=400 \\
A_{\mathrm{s}}=400\end{array}$ & $\begin{array}{l}36 \cdot 1 \\
35 \cdot 8\end{array}$ & $\begin{array}{l}3.7 \\
3.8\end{array}$ & $\begin{array}{l}14 \\
14\end{array}$ & $\begin{array}{l}79.9 \\
79.9\end{array}$ \\
\hline $\begin{array}{l}\text { B1 } \\
\text { B2 }\end{array}$ & $\begin{array}{l}A_{s}=900 \\
A_{s}=900\end{array}$ & $\begin{array}{l}39 \cdot 0 \\
39 \cdot 2\end{array}$ & $\begin{array}{l}4 \cdot 3 \\
4 \cdot 3\end{array}$ & $\begin{array}{l}28 \\
28\end{array}$ & $\begin{array}{l}119 \cdot 8 \\
119.8\end{array}$ \\
\hline $\mathrm{C} 1$ & $\begin{array}{l}A_{s}=900 \\
A_{s}^{\prime}=400\end{array}$ & 35.1 & $3 \cdot 7$ & 35 & 139.8 \\
\hline $\mathrm{C} 2$ & $\begin{array}{l}A_{s}=900 \\
A_{s}^{\prime}=400\end{array}$ & 36.1 & 3.9 & 35 & $139 \cdot 8$ \\
\hline
\end{tabular}

*Beams in series A and B were also reinforced with 2-10 M (10 mm diameter) bars at the top for the purpose of holding stirrups in place.

\section{Experimental programme}

To study the influence of shrinkage on deformations, three groups of two identical beams were tested (Divakar 1983) at The University of Calgary (see table 1). The test variables were the amount of the tension and compression reinforcement, the age at testing and the exposure conditions. All six beams were $200 \mathrm{~mm}$ wide, $300 \mathrm{~mm}$ deep and $3800 \mathrm{~mm}$ long with a span of $3000 \mathrm{~mm}$ and an overhang of $600 \mathrm{~mm}$ intended for shrinkage curvature measurement in the uncracked state. The concrete cover to the longitudinal bars was $40 \mathrm{~mm}$ for all beams. Figure 3 shows the details of the test beams with reinforcement arrangement. The concrete mix was proportioned according to ACI-211-1974 for a design strength of $35 \mathrm{MPa}$. Deformed bars no. 10, 15 and 20 with a minimum specified yield strength of $400 \mathrm{MPa}$ were used. The beams were kept in a quiescent state till the day of testing by keeping them in the curing room with $100 \%$ relative humidity.

The beams were subjected to a bending moment equal to $60 \%$ of their flexural capacity by applying two equal point loads at quarter points of the span. Under this moment, a steel strain of 0.001 was reached in the tensile reinforcement. After marking the cracks and measuring the crack widths at the level of the tension reinforcement and at the bottom surface, the load was gradually removed. The beams were then moved to a storage room and placed on their sides on masonry blocks

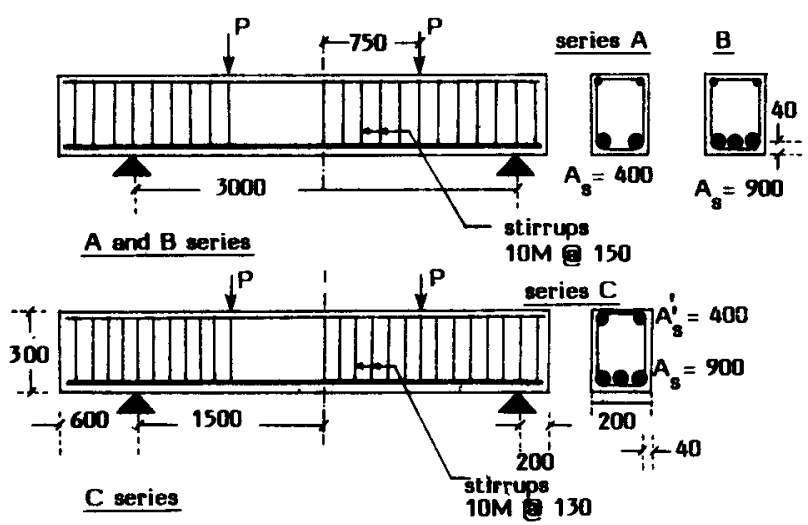

all dimensions in $\mathrm{mm}$

Figure 3. Details of test beams $A, B$ and $C$ series. 
covered with multiple layers of polythene sheets to reduce friction between the beam and the block. Overhangs were provided at both ends of the beam to minimise deflections due to dead load.

For the measurement of shrinkage curvature, brass points were fixed for a gauge length of $500 \mathrm{~mm}$ in the cracked and uncracked portions of the beam (see figures 4 \& 5) and strain measurements were made with a demountable mechanical strain gauge of $500 \mathrm{~mm}$ gauge length. This instrument reads with an accuracy of 2 microstrains, with temperature compensation.

In order to establish the effect of exposure conditions (i.e., the relative humidity) on deformations, beams $\mathrm{A} 1, \mathrm{~B} 1$ and $\mathrm{C} 1$ were exposed to drying conditions while the comparison beams A2, B2 and C2 were kept continuously moist by wrapping them in wet burlap and polythene sheets and by spraying water onto the burlap at frequent intervals. Beams A1 and B1 were stored in an environmental room where the temperature and relative humidity were maintained at $+21^{\circ} \mathrm{C}$ and $50 \%$ respectively. Beam $\mathrm{C} 1$ was stored in the concrete laboratory and a continuous record of the temperature and humidity was obtained. While the temperature hovered around $+20^{\circ} \mathrm{C}$, the relative humidity fluctuated between 20 and $35 \%$. Companion specimens in the form of cylinders (152 mm diameter and $305 \mathrm{~mm}$ height) were also stored in the same environment as their beams and strain readings were taken periodically with a $203 \mathrm{~mm}$ Demec strain gauge.

\subsection{Experimental results}

On beams subjected to drying as well as wetting, shrinkage strains were measured

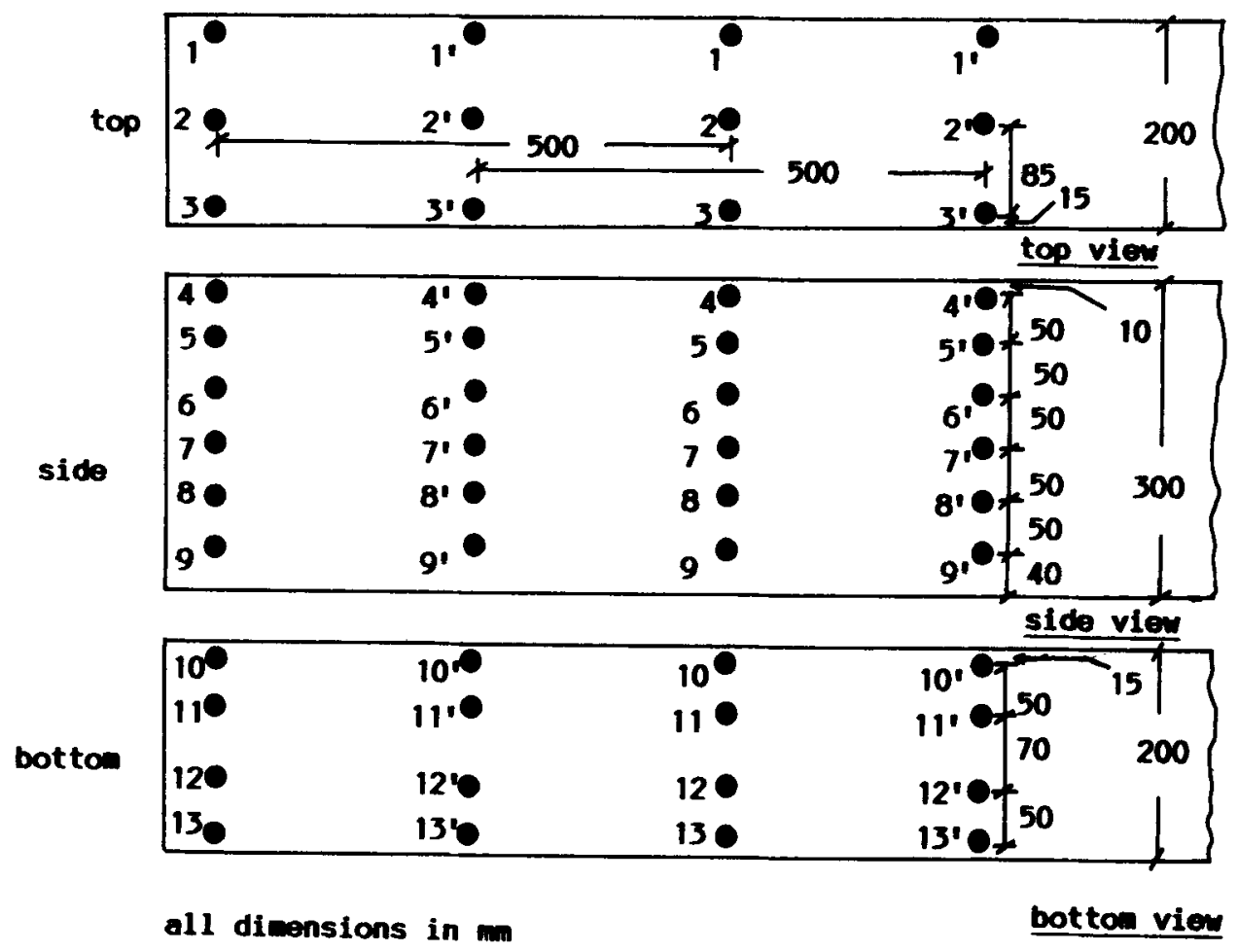

Figure 4. Shrinkage strain measurement in the uncracked state. 

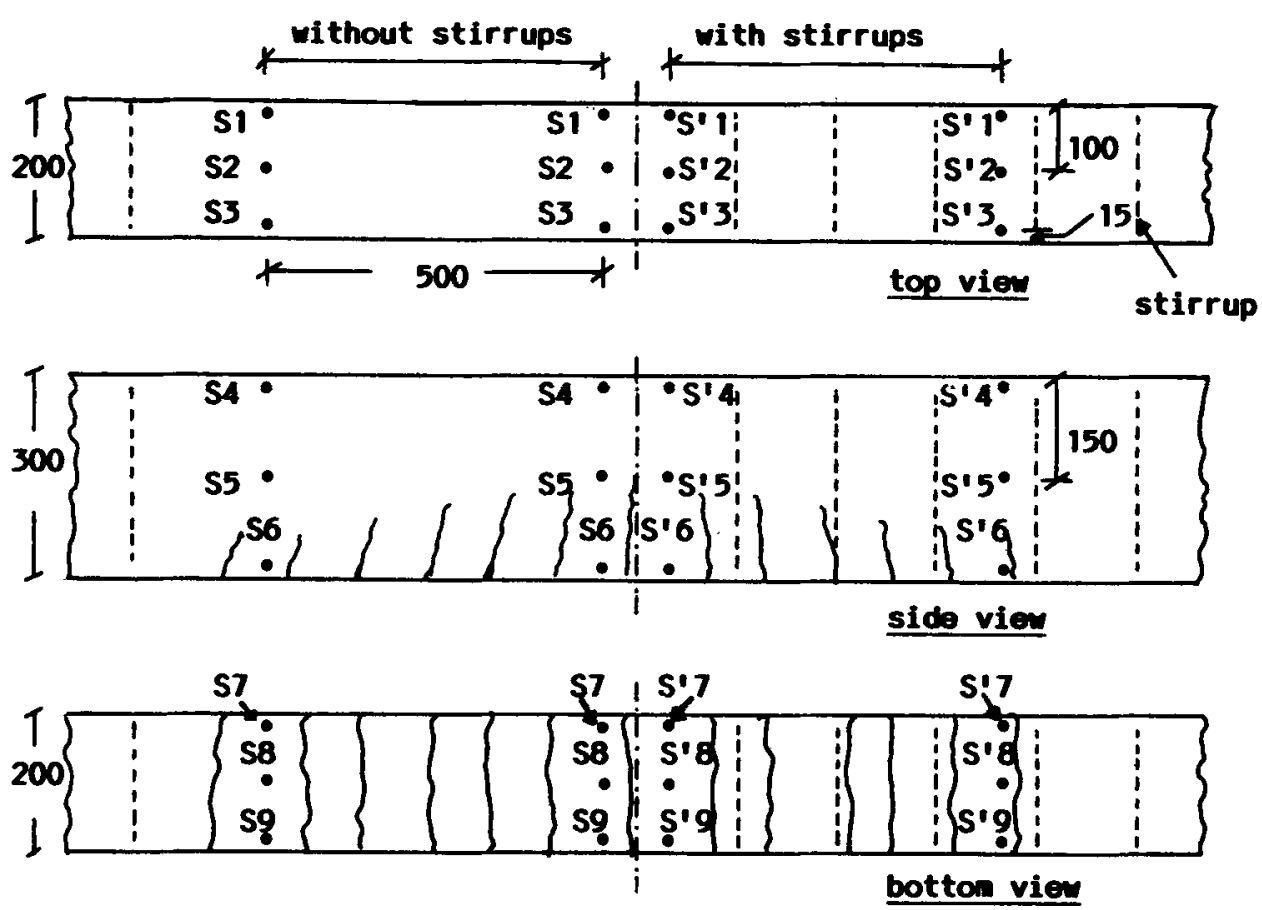

all dimensions in $\mathrm{mm}$

Figure 5. Shrinkage strain measurement in the uncracked state.

over a gauge length of $500 \mathrm{~mm}$ on top, side and bottom faces of the beam. The designations of the gauge lines are shown in figures $4 \& 5$. These strains were measured at two sections in both cracked and uncracked states and were averaged for computing the resulting deformations.

Figures $6 \& 7$ show the shrinkage strains plotted at different gauge line positions. The strain values plotted at top and bottom are the average of strains at top and bottom faces respectively. A least squares regression line was fitted through these

beans $B 1 \& B 2$ - uncracked state

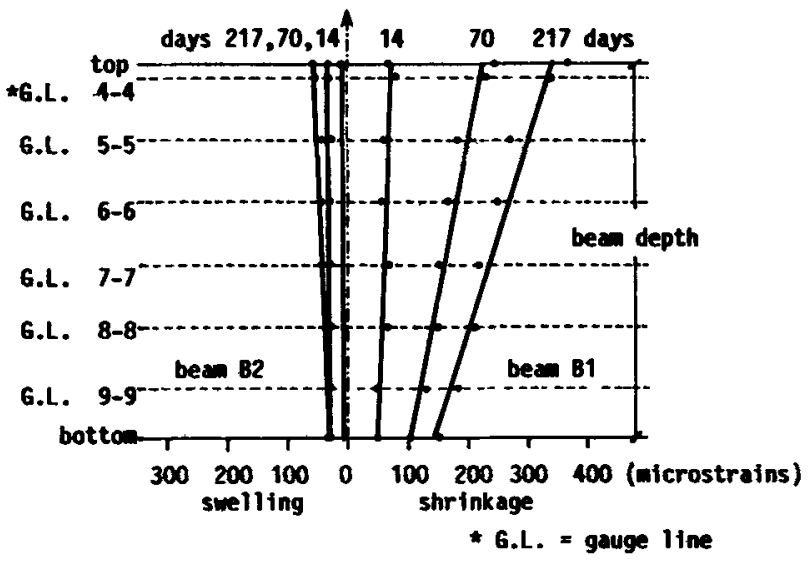

Figure 6. Swelling and shrinkage strain profiles of beams in series B - uncracked state. 


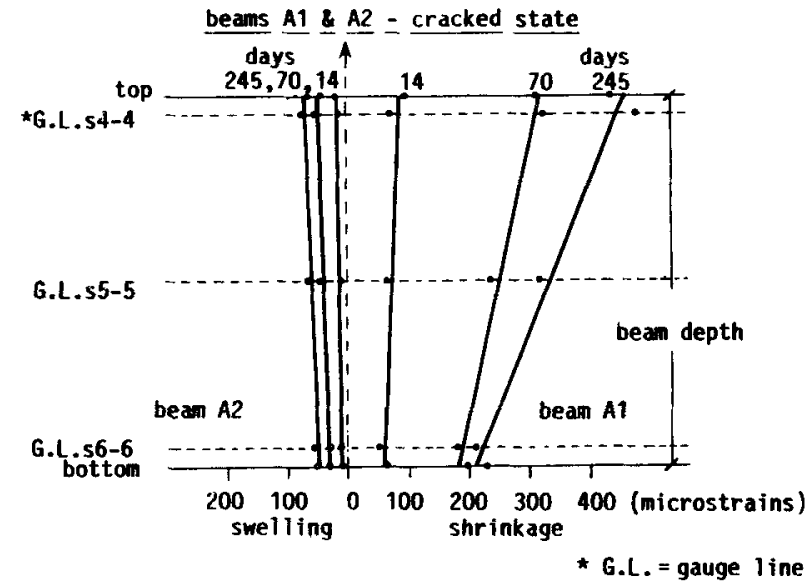

Figure 7. Swelling and shrinkage strain profiles of beams in series $A$ - uncracked state.

data points to obtain the strain profiles for the purpose of computing observed shrinkage curvature in both cracked and uncracked states. It is important to note that the strains at gauge line S3-S3 and S4-S4 in the cracked state (see figure 8) and at 3-3 and 4-4 in the uncracked state (see figure 9) were not the same.

In all three beam series, it was clearly observed that the curvatures in the cracked state were higher than the uncracked state (see for e.g., figure 10). The influence of compression reinforcement was clearly observed to decrease shrinkage deformations. This is evident from figure 11 in which the curvatures of beams $\mathrm{Bl}$ and $\mathrm{Cl}$ have been plotted. Note that $\mathrm{B} 1$ and $\mathrm{C} 1$ had the same amount of tension reinforcement, but $\mathrm{C} 1$ had a higher percentage of compression reinforcement. Also, an increase in the tension reinforcement ratio was found to increase curvatures due to shrinkage (see Divakar 1983, for more details).

The strains due to swelling (see figures $6 \& 7$ ) were quite small compared to shrinkage strains, but they clearly substantiate the fact that creep effects due to dead load deflections .were insignificant.

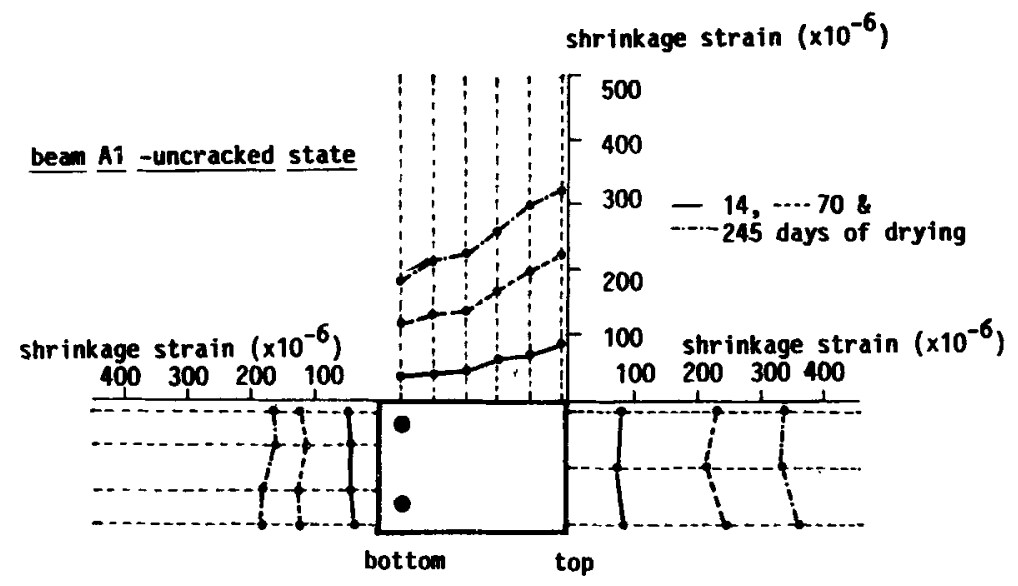

Figure 8. Detailed representation of measured shrinkage strains in beam A1 - uncracked state. 




Figure 9. Detailed representation of measured shrinkage strains in beam A1 - cracked state.

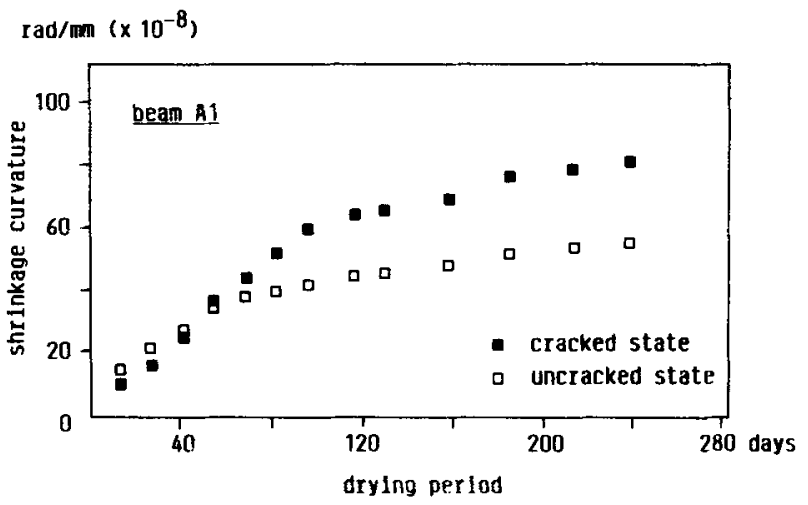

Figure 10. Observed shrinkage curvatures in cracked and uncracked states - beam Al.

It was not possible to explicitly determine the effect of curing period on shrinkage deformations as other quantities such as reinforcement ratio were also varied. However, free shrinkage data collected on control specimens (cylinders) did indicate that specimens cured for a shorter period shrink more than those subjected to prolonged curing period. Many shrinkage prediction models such as ACI Committee

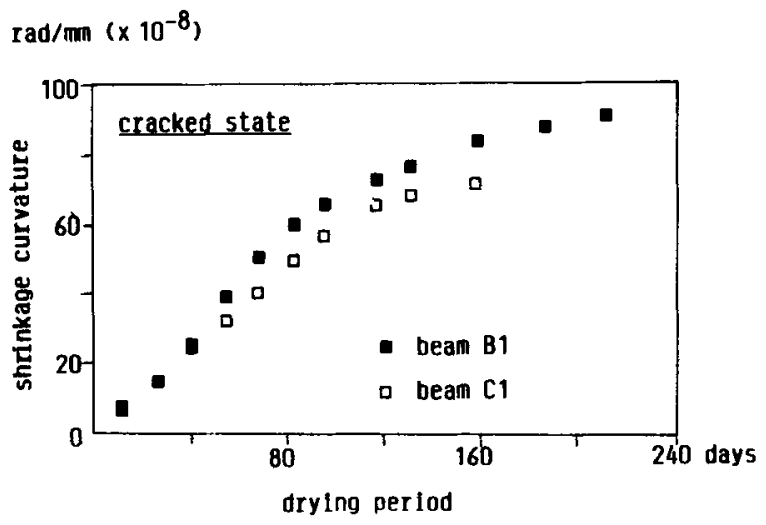

Figure 11. Effect of compression reinforcement on measured shrinkage curvatures. 


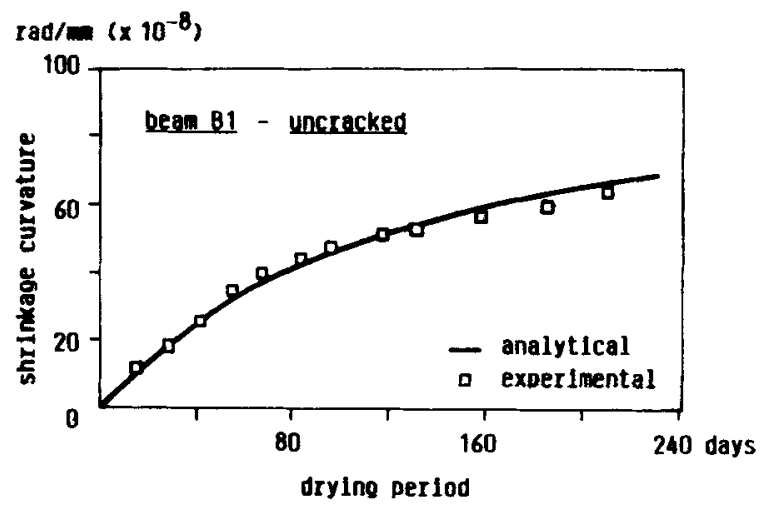

Figure 12. Comparison of analytical and experimental shrinkage curvatures - uncracked state.

209 (1978) and CEB-FIP Model Code (1978) do not consider this effect whereas the model by Bazant \& Panula (1976) accounts for this effect.

\section{Discussion}

The shrinkage prediction model proposed by Bazant \& Panula (1976) was used for computing the free shrinkage of beams. Creep coefficients were estimated using the ACI Committee 209 (1978) recommendations and were adjusted using the aging coefficients computed by Dilger (1982). The analytical model discussed here was numerically evaluated for all three beams at a time step of 7 days using the creep coefficients and shrinkage strains computed from above. The variation of modulus of elasticity of concrete with time was accounted for by using the relation suggested by ACI Committee 209 (1978).

Figures 12 and 13 show the comparison of analytical and observed shrinkage curvatures in the uncracked state. The comparison in the cracked state is shown in figures $14 \& 15$. From these figures, it can be seen that the comparison is quite accurate.

The analytical model was also used to predict the test data of other investigators. As an example, the test data of Mohammedbhai \& Taylor (1974) who tested concrete slabs was chosen. Figure 16 shows the details of reinforcement and slab thicknesses

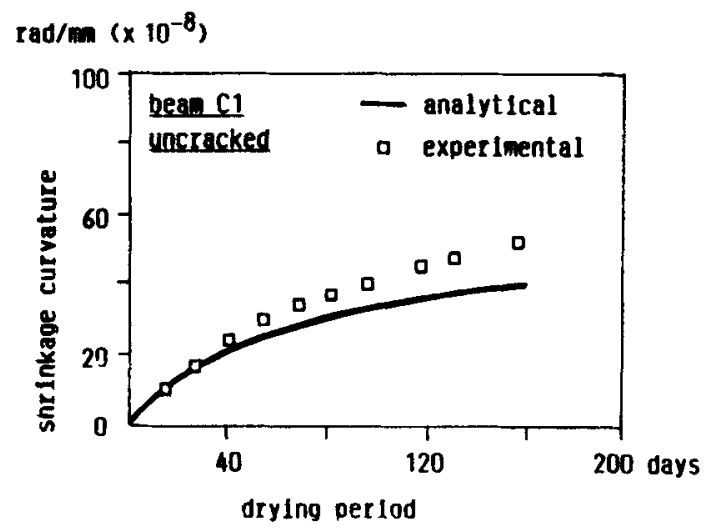

Figure 13. Comparison of analytical and experimental shrinkage curvatures - uncracked state. 


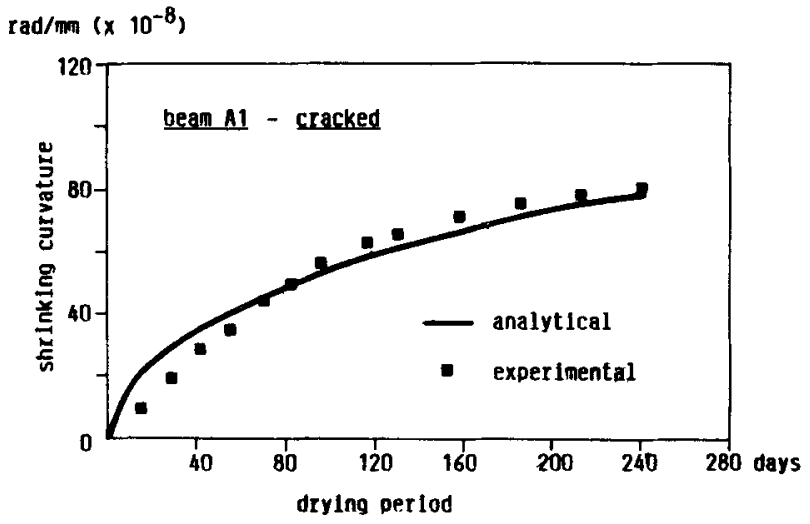

Figure 14. Comparison of analytical and experimental shrinkage curvatures - cracked state.

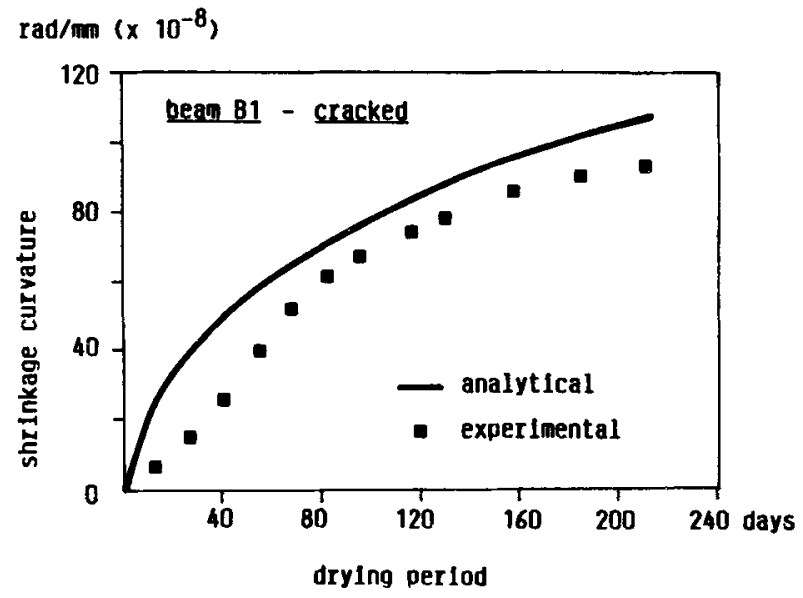

Figure 15. Comparison of analytical and experimental shrinkage curvatures - cracked state.

of the two series tested by them. Figures 17 and 18 show the comparison between analytical and observed mid-span deflections of the slabs. Since the estimated dead weight deflections were small, their time dependent influence on shrinkage deflec-

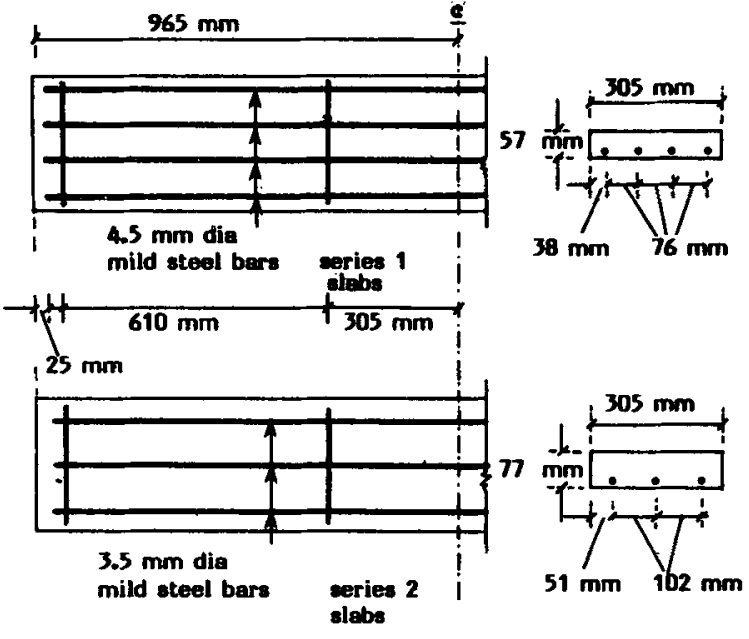

$3 \mathrm{~mm}$ cover to main bars in both series
Figure 16. Details of slabs tested by Mohammedbhai \& Taylor (1974). 


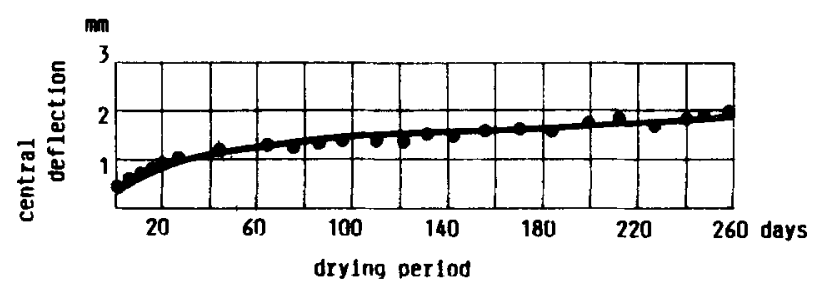

Figure 17. Comparison of analytical and experimental (Mohammedbhai \& Taylor 1974) central deflections - series I slabs.

tions has been ignored in the calculations. The comparison is again quite accurate. Note that for series 2, there was an accidental wetting of the slabs due to water leakage during which most of the shrinkage deflections were recovered. With the continuation of drying, the deflections resumed their previous values.

The slight discrepancies observed between analytical and observed deformations could have arisen from inaccurate estimate of the creep coefficient and to some extent from inexact estimation of free shrinkage strains. Apart from these, there are other influencing mechanisms which still need to be understood and modelled. For structural engineering calculations, the method discussed here can be concluded to be quite accurate.

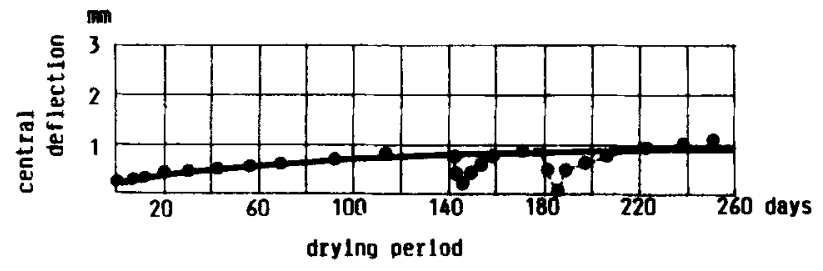

Figure 18. Comparison of analytical and experimental (Mohammedbhai \& Taylor 1974) central deflections - series II slabs.

\section{Concluding remarks}

Shrinkage of concrete significantly contributes to overall deformations of concrete structures. To analyse its effects, an analytical model was proposed by the authors. The validity of the model was confirmed by conducting experimental investigation. It was found that shrinkage deformations were significantly different in cracked and uncracked states. For accurate estimation of long term deflections, it becomes necessary to account for this difference. Prolonged curing as well as introduction of compression reinforcement was found to result in reduced shrinkage curvatures. Satisfactory agreement between analytical and experimental deformations was observed. The equations presented here can be used in the serviceability analysis of concrete members.

\section{List of symbols}

$\begin{array}{ll}A_{c} & \text { area of net concrete section; } \\ A_{s}, A_{s}^{\prime} & \text { area of steel in tension and compression; } \\ b & \text { width of the beam; } \\ c & \text { concrete cover over rebars; } \\ d & \text { effective depth of the beam; } \\ d_{a} & \text { active depth of a cracked beam; }\end{array}$


$E_{c} \quad$ short term elastic modulus of concrete;

$E_{s} \quad$ elastic modulus of steel;

$h \quad$ overall depth of the section;

$I_{c} \quad$ moment of inertia of net area of concrete about the neutral axis;

$I_{\text {eff }} \quad$ effective moment of inertia of the cross-section;

$L \quad$ span of the member;

$M_{a} \quad$ applied moment;

$M_{c r} \quad$ cracking moment;

$n_{0} \quad$ initial modular ratio;

$n^{*} \quad$ creep transformed modular ratio;

$r \quad$ radius of gyration;

$t \quad$ time in days;

$t_{0} \quad$ time in days when drying begins;

$y_{1} \quad$ distance to the centroid of tension steel from the centroid of the concrete section;

$y_{2} \quad$ distance to the centroid of the compression steel from the centroid of the net concrete section;

$\beta_{1} \quad$ constant for bond properties used in the distribution ratio equation;

$\beta_{2} \quad$ constant for load duration used in the equation for distribution ratio;

$\beta_{11}-\beta_{\mathrm{D}} \quad$ coefficients;

$\varepsilon_{s h} \quad$ free shrinkage of concrete;

$\psi_{s h 1}$

$\psi_{s h 2}$

$\psi_{\text {shm }}$

$\varphi$

$\rho_{1}$ shrinkage curvature of an uncracked section; shrinkage curvature of a cracked section; overall shrinkage curvature of a cracked member; creep coefficient of concrete;

tension reinforcement ratio,

$\rho_{2} \quad$ compression reinforcement ratio;

$\sigma_{s} \quad$ stress in steel at a cracked section;

$\sigma_{s r} \quad$ stress in steel at first cracking;

$\chi \quad$ aging coefficient;

$\zeta \quad$ distribution ratio.

\section{References}

Abdul Wahab H M S, Jaffar A S $1983 \mathrm{~J}$. Am. Concrete Inst. 80: 109-115

ACI Committee 4351966 (Reaffirmed 1979) J. Am. Concrete Inst. 63: 637-674

ACI Committee 3181977 (Revised 1984) Building code requirements for reinforced concrete, ACI 318-1977

ACI Committee 2091978 2nd draft, Am. Concrete Inst., Detroit

Bazant Z P, Panula L 1976 Mater. Struct. (RILEM) 11: 307-316

Beeby A W 1973 Bulletin D'Information, CEB, Paris No. 90, pp. 3.1-3.17

Branson D E 1977 Deformation of concrete structures (New York: McGraw Hill)

CEB-FIP 1978 Model code for concrete structures, CEB, Paris

CEB-FIP 1981 Cracking and deformation. Bulletin D'Information No. 143, Lausanne, Switzerland

Dilger W H, Neville A M 1970 IABSE Reports of the working Commission, Vol. 5, pp. 253-260

Dilger W H 1982 Prestressed Concrete Inst. J. 27: 98-110

Divakar M P 1983 Effect of shrinkage on cracking and deformation of R. C. beams M.Sc. thesis, The University of Calgary, Calgary, Canada

Divakar M P, Dilger W H 1985 Proceedings of CSCE Annual Conference, Saskatoon, SK, Canada pp. 393-412

Elvery R H, Shafi M $1970 \mathrm{~J}$. Am. Concrete Inst. 67: 45-52

Mohammedbhai G T G, Taylor R 1974 Proc. Inst. Eng. Part 2: Res. Theory 57:67-82

Shafi M 1967 Shrinkage stresses in composite concrete beams, Ph.D. thesis, University of London, UK

Trost H, Mainz B 1969 Beton-Stahlbetonbau 64: 142-146 